\title{
In Vitro and in Vivo Evaluation of Pectin-based Melatonin Nanoparticles for the Treatment of Inflammatory Bowel Disease
}

\author{
Serkan Yener \\ Turkish Medicines and Medical Devices Agency \\ Kazime Gonca Akbulut \\ Gazi University Faculty of Medicine \\ Resul Karakuş \\ Gazi University Faculty of Medicine: Gazi Universitesi Tip Fakultesi \\ Deniz Erdoğan \\ Gazi University Faculty of Medicine: Gazi Universitesi Tip Fakultesi \\ Füsun Acartürk ( $\square$ acarturk@gazi.edu.tr) \\ Gazi University Faculty of Pharmacy https://orcid.org/0000-0001-9515-750X
}

\section{Research Article}

Keywords: Inflammatory Bowel Disease, Crohn's Disease, Melatonin, Pectin Nanoparticle

Posted Date: March 30th, 2021

DOI: https://doi.org/10.21203/rs.3.rs-303104/v1

License: (c) (1) This work is licensed under a Creative Commons Attribution 4.0 International License. Read Full License 


\section{Abstract}

Inflammatory bowel disease (IBD) is a general term including long-term inflammatory disorders of all or some parts of the digestive system. Nanoparticles (NPs) can accumulate in the inflamed zone independently of the polymers' mucoadhesive character.

The aim of this study was to prepare and investigate the melatonin loaded pectin-based nanoparticles for Inflammatory Bowel Disease (IBD). Melatonin (MEL) was loaded into nanoparticle system with a modified ionotropic-gelation method. In vitro characterization studies of the nanoparticles were carried out.

The effectiveness of the oral and intracolonically administered nanoparticles were investigated in 2,4,6-trinitrobenzene sulfonic acid (TNBS)-induced colitis rats. The indicators of oxidative stress in the colonic tissue like nitric oxide, malondialdehyde, glutathione, tumor necrosis factor-alpha, Interleukin (IL)-10, and IL-17 levels were investigated. In addition, the histological evaluation was performed.

The mean diameter, zeta potential and polydispersity index values of the obtained nanoparticles were $75.3 \pm 3.3 \mathrm{~nm}, 24.24 \pm 1.03 \mathrm{mV}$ and $0.109 \pm 0.067$, respectively. The in vitro drug release studies showed that $84.0 \pm 0.7 \%$ of the drug was released from the nanoparticles for $8 \mathrm{~h}$. MEL-loaded pectin nanoparticles ameliorated the TNBS-induced colitis. Treatment of the melatonin decreased the damage score by $73.2 \%$ in oral and by $67.1 \%$ in intracolonic route, respectively. A meaningful decrease was observed in colonic fibrosis, oxidative stress, and inflammatory parameters of the colon accompanying histologic injury. The results of the experiments and histological data showed that MEL-loaded calcium pectinate nanoparticle may be a promising alternative in colonic tissue damage which develops due to oxidative stress in IBD.

\section{Introduction}

Inflammatory Bowel Disease (IBD) is a term for two conditions, mainly ulcerative colitis and Crohn's disease. They are autoimmune chronic inflammatory disorders affecting more than three million people in the west of the world, and a frightening increase in Asia has been noticed presently. In the last a few years, the elucidation of mutations in different genes has been helpful in identifying the pathways causing colitis[1].

The etiological pathways of IBD have not been cleared completely yet. However, increase in tissue reactive oxygen product levels, decrease in the antioxidant capacity, and increased proinflammatory mediators' secretion are the accepted properties of IBD [2]. Severe inflammation caused by oxidative stress is the lead actor of the pathogenesis in IBD [3]. Prevention of cell membrane from lipid peroxidation, cleaning free radicals, and enhancing the antioxidant capacity of colonic tissue offer a useful alternative cure for IBD [4]. In addition to reactive oxygen products, nitric oxide (NOx) is an important pathophysiological actor of colonic injury in IBD [5].

Melatonin (N-acetyl-5-methoxytryptamine) (MEL) is a potent endogenic antioxidant which is secreted by pineal gland in a circadian rhythm. In addition to brain, elavated MEL levels were also found in gut [6].

MEL and its active metabolites protect the cellular membrane integrity by preventing lipid oxidation of cell membrane and reduce the oxidative stress effectively by scavenging various types of free radicals which are composed of different pathways. Due to its small particle size and dissolution ability in lipids, MEL can pass by cell membrane and reach different cell sections effortlessly. Therefore, severe oxidative injury in all kinds of tissues is reduced [7]. MEL, as a protector, increases the tissue glutathione (GSH) levels and decreases nitric oxide (NOx) and malondialdehyde (MDA) levels indirectly [8][9][10] [11].

MEL has also important antiinflammatory effects, as it reduces inflammatory cytokine levels, such as Tumor necrosis factor-alpha (TNF-a), Interleukin (IL)-10 and IL-17 [8][9][10][11][12].

High antioxidant capability, powerful antiinflammatory efficiency, and high levels in gut make MEL an important candidate drug to decrease free radicals, oxidative damage, and/or ameliorate ulcerated regions in IBD.

Preventive and therapeutic effects of MEL are widely observed in different types of chemicals induced colitis animal models. It was reported that administered MEL dose (from $2.5 \mathrm{mg} / \mathrm{kg}$ to $100 \mathrm{mg} / \mathrm{kg}$ ) administration route (intracolonic, intraperitonal and oral), and the duration of MEL treatment (from 2 to 27 days) in rats vary over a wide range in literature [8][9][10][11][12] [13][14][15][16][17].

Colon specific drug delivery systems can be administered orally and/or rectally. Conventional oral medications are highly absorbed before reaching the colon; on the other hand, rectal preparations are insufficient to reach the ascending colon region. Therefore, colon-targeted drug delivery systems have come into prominence. These systems benefit from the specific physiological characteristics of the colon to expose the formulation content in the desired colon region. Gut has different favorable specifications such as many different types of digestive enzymes. Some kind of polysaccharides like pectin can be digested by the enzymes which are only produced by gut flora. Therefore, different types of polysaccharides can be used to design colon-targeted drug delivery systems which control enzymatical degradation [18].

Pectin is a heterogenous, negatively charged, and watersoluble polysaccharide derived from plants. It is formed by linear 1,4-linked a-D-galacturonic acid units. It is especially used as an additive agent in the food industry. In recent years, an increase is observed in its use as an excipient in the pharmaceutical industry. It is resistant to human digestive enzymes, but can be degraded entirely by the enzymes which are only produced by gut flora called pectinase. The esterification [degree of esterification (DE)] and amidation [degree of amidation (DA)] ratio of carboxyl groups determine the physicochemical characteristics of pectins [19]. Several researchers successfully loaded several kinds of drugs into pectin-based nanoparticles (NPs) by using an ionotropic 
gelation method to perform a colonic delivery system [20][21][22]. Nizic et al. prepared and characterized sprey-dried melatonin-loaded pectin/ hypromellose microspheres for nasal delivery [23].

In inflamed gut diseases, their phagocytic activities and infiltration rates are induced by secreted cytokines [24]. Selective uptake of NPs into immun system cells provide private cumulation in inflamed gut regions. Inflamed gut region is stimulated to produce the elevated levels of mucus in order to protect against oxidative injury. This pathophysiological change allows the polysaccharide polymer to adhere more powerfully to the inflamed tissue. In addition, a thicker mucus layer in ulcerated regions is reported in IBD because of elevated mucus secretion. The use of mucoadhesive biopolymers extends the retention time of drugs at inflamed sites of gut. These novel and promising approaches elevate the targeting success of drug carrier systems [25]. In addition, very high concentrations of positively charged proteins were found in the ulcerated lesions. Thus, electronegative particular systems preferably bind to the ulcerated colonic tissues due to electrostatic interactions. On the contrary, no electrostatic adherence to the healthy colonic regions is expected [26].

In recent years, a new treatment approach, which aimed to increase the number of immune related cells (neutrophils, natural killer cells, mast cells, macrophages), has gained importance due to the increased immune response in the region of IBD [27]. The specific cumulation of the NPs in the site of inflamed tissue is allowed by NP uptake into these phagocytic cells and impaired gut mucosal integrity, which causes increased permeability in ulcerated gut region. This selective cumulation is particle size dependent, and an increased cumulation is observed with NP diameters [28][29][30][31]. Immune related cells in gut can easily fagosite the particular substances which have a diameter less than $4 \mu \mathrm{m}$ [32]. These studies have shown that intercorporation of antioxidant and anti-inflammatory drugs with NP drug delivery systems, which were designed with mucoadhesive polymers, will be very effective in IBD.

In this study, we aimed to design calcium pectinate NPs containing MEL and evaluate the effectiveness of orally and intracolonically administered NPs from biochemical, immunological, and histological perspectives. To the best of our knowledge, this is the first study on the preparation and investigation of the effectiveness of pectin-based nanoparticles loaded melatonin for IBD.

MEL is dissolved at different concentrations basicly in isotonic saline solution and has been administered either thorough intracolonic (IC) or intraperitoneal (IP) route in previous studies [8][9][10][11][12][13][17] which evaluated the antioxidant efficacy of MEL on IBD. To the best of our knowledge, this is the first investigation to prove dual antioxidant and antiinflammatory effects of MEL loaded pectin-based NPs, which were given orally and intracolonically on trinitrobenzene sulfonic acid (TNBS) induced colitis in rats.

\section{Materials And Methods}

\section{Materials}

Pectin (DE is twenty-eight percent and DA is twenty percent) was kindly gifted by CP Kelco (Denmark). MEL, trichloroacetic acid, butylhydroxytoluene, naphthylethylenediamine dihydrochloride and Pectinex (pectinolytic enzyme from Aspergillus aculeatus) were supplied from Sigma (USA). Sodium hydroxide, sodium phosphate monobasic, calcium chloride, sodium chloride, and TNBS were purchased from Merck (Germany). Analytical grade solvents, chemicals, and purified water $\left(18.2 \mathrm{M} \Omega \mathrm{cm}\right.$ at $\left.25^{\circ} \mathrm{C}\right)$ were used throughout the study (Millipore Direct-Q ${ }^{\circledR}, \mathrm{Billerica}, \mathrm{USA}$ ).

\section{Preparation of the formulation}

Calcium pectinate based NP formulations were designed by a previously modified polyelectrolyte complexation method [33]. In that study, a factorial design was used to investigate the impact and relationship of the parameters used in the preparation of NP formulation on the generated NP. This factorial design comprised of five different formulation parameters (pectin concentration, $\mathrm{CaCl}_{2}$ concentration, pectin to $\mathrm{MEL}$ ratio, cross-linking time, and stirring rate) which had two different (low and high) values used in the preparation of NP $\left(2^{5}\right)$. The prepared formulations were characterized by considering particle size (PS), zeta potential (ZP), and polydispersity index parameters (measured by Malvern Zeta Nanosizer ${ }^{\circledR}$ ). MEL release studies from NPs were performed at $\mathrm{pH} 6.8$ buffer system. According to these results, the optimum NP formulation was determined, and further studies were performed with this NP formulation. The formulation parameters of the optimum nanoparticle formulation are shown in Table 1.

\section{pH measurements}

24 hours after the production of NPs, triplicate samples were measured with a pH meter (Schott CG 840, Mainz, Germany) for each NP formulation at 25 $\mathrm{C}^{\circ}$.

\section{Morphology of the NP formulation-Transmission electron microscopy (TEM) studies}

In laminar airflow, one drop of the prepared NP suspension was dropped onto the carbon film coated copper plate and dried by standing overnight at room temperature in a covered petri dish. The samples prepared in this way were placed in the TEM device and images were taken.

\section{Encapsulation efficiency (EE)}

MEL amount in the NP formulations was detected by a spectrophotometric method (UV-Visible Spectrophotometer Shimadzu, Japan) at a wavelength of $278 \mathrm{~nm}$. Indirect method ([34][35]) was used to calculate the encapsulation efficiency by centrifuging the NP dispersion at $20,000 \mathrm{G}$ for 30 min at $25^{\circ} \mathrm{C}$ (AvantiTM J-25 Centrifuge, Shimadzu, Japan) and by assessing the MEL amount in the supernatant. EE (\%) was calculated with the equation [(W- 
Ws)/W] $100 \%$, where Ws is the MEL amount in the supernatant and W is the firstly loaded MEL amount in a NP formulation. The measures of each formulation sample were triplicated.

\section{Determination of the unbound calcium content in the formulation}

Atomic absorption spectroscopy was used to assay unbound calcium content in the NP formulation. Nitrous oxide was selected as gas burner, and acetylene was selected as fuel to obtain a flame. The light source hollow cathode $\left(\mathrm{Ca}^{2+}\right)$ was used, and the intensity of light was adjusted to $10 \mathrm{~mA}$.

\section{In vitro MEL release studies from the NP formulations}

In vitro release of the MEL from NPs was performed by USP dissolution apparatus I in which dialysis bags were inserted at a rotating speed of 50 rpm in $250 \mathrm{~mL}$ of different buffer mediums at $37 \pm 1^{\circ} \mathrm{C}$ [35] [36][37]. Two $\mathrm{ml}$ of NP sample was added from one end of dialysis tube (Dialysis bag: D-0405, SigmaAldrich Corp., St. Louis, MO, USA, pore size of $12 \mathrm{KDa}$ ), which was firmly tied. The other end of the tube was then closed to form a bag which was immediately put into the basket. At pre-determined time intervals, $2 \mathrm{ml}$ sample was withdrawn from the medium, and the same volume of fresh buffer was added to medium immediately. The MEL concentration was assayed spectrophotometrically at $278 \mathrm{~nm}$. The MEL release profile was investigated in three different mediums ( $\mathrm{pH}$ 1.2, $\mathrm{pH} 7.4$ and pH 6.8 buffer systems) [38] in order to compare the percentages of the cumulative MEL released in stomach, small intestine, and large intestine, respectively.

After an oral dosing, dosage units reach stomach first and move to the small intestine in 2 hours by gastric emptying. Dosage units pass through the small intestine by peristaltic movement for 3 hours and finally arrive at the large intestine. At the end of $8^{\text {th }}$ hour, intestinal emptying occurs. Therefore, we chose these gastric and intestinal physiological conditions for our MEL release studies. In addition, calcium pectinate based NPs may not be digested by the enzymes involved in the human digestive system. Therefore, in our release studies, $2 \%$ of Pectinex enzyme was added to the release medium for the last 3 hours in order to simulate in vivo colonic flora.

The NPs were monitored for MEL release firstly for 2 hours in $0.1 \mathrm{M} \mathrm{HCl}$, between 2-5 hours in a pH 7.4 phosphate buffer, and finally between 5-8 hours in a $\mathrm{pH} 6.8$ phosphate buffer containing $2 \%$ Pectinex at $37^{\circ} \mathrm{C}$, respectively, due to average gastric and intestinal emptying rate.

\section{Kinetics of the drug release}

The obtained MEL release data were fitted into zero order, first order, and Higuchi's kinetics, respectively. The optimal MEL release kinetic was chosen by linear regression calculation. $\mathrm{R}^{2}>0.95$ (the proximity of the value to the 1.000 ) was established for linearity. The rate constants of each different kinetic were calculated from the slope of the lines.

\section{Mucoadhesion studies}

The mucoadhesion ability of the NP formulation was investigated by a texture analyzer (TA. XT. Plus Texture Analyzer, Stable Micro Systems, London, UK), which has a mucoadhesive holder equipment. The cut and cleaned rat colon samples were kept at $-80^{\circ} \mathrm{C}$. There are two kinds of tissue samples used to compare the mucoadhesion of NPs to healthy and TNBS induced colitis mucosa. A $2 \mathrm{~mm}$ thin tissue sample was cut from the inside of the frozen colon sample and pasted immediately to the edge of the probe of the analyzer with cyanoacrylate glue. The in vitro mucoadhesion testing method was based on the measurement of the work (N.mm), work of mucoadhesion $\left(\mathrm{mJ} / \mathrm{cm}^{2}\right)$ and force $(\mathrm{N})$ needed to detach a sample of rat colonic mucosa from a NP formulation. The testing conditions and instrumental parameters were defined by optimization studies in the literature [37].

\section{Stability studies}

The stability of the optimized NP formulation was investigated for 6 months at three different climate conditions: $4^{\circ} \mathrm{C} /$ ambient humidity, $25^{\circ} \mathrm{C} / 60 \%$ relative humidity, and accelerated temperature $40^{\circ} \mathrm{C} / 75 \%$ relative humidity. $\mathrm{pH}$, mean particle size, polydispersity index, MEL concentration, and zeta potential values were evaluated at predetermined time intervals.

\section{In vivo studies}

Local Ethics Committee for Animal Experiments of Gazi University approved our animal experimental protocol (G.U. ET-12.026). 10 mg/kg MEL loaded NP formulation was administered via intracolonical and oral route to colitis induced rats by TNBS, and the effectiveness of MEL was investigated from biochemical, immunological, and histological perspectives.

\section{Animals}

Wistar male rats $(0.25-0.30 \mathrm{~kg}, 18$ weeks old) were chosen to perform in vivo studies. The rats were housed individually in metabolic cages to monitorize the symptoms of IBD due to TNBS administration, such as body weight changes, food/water intake, and diarrhea control. The rats were kept under uniform and controlled temperature $\left(25^{\circ} \mathrm{C}\right)$, lighting (normal sunlight light/dark circadian rhythm), and humidity conditions. The rats were given ad libitum access to standard rat pellets and tap water. Only food access was stopped overnight before the administration of TNBS. The fecal output of all the rats in the cages was recorded by arbitrary criteria which were defined as: 1) diarrhea and 2) bloody diarrhea.

\section{Colitis induction with TNBS in the rats}


All the animals were fasted for 16 hours prior to the administration of TNBS. Firstly, the whole body weights of all the rats were noted. Xylazine (5 mg/kg) + ketamine $(50 \mathrm{mg} / \mathrm{kg}$ ) was administered via intramuscular (IM) route to anesthetize the rats. The TNBS solution (dissolved in ethanol $50 \% \mathrm{v} / \mathrm{v}$ ) was used to induce colitis in the rats [12][39]. According to the body weights of the rats, the TNBS $(80 \mathrm{mg} / \mathrm{kg})$ was administered via IC route in a total volume of $0.6 \mathrm{ml}$ by inserting a stainless steel gavage $8 \mathrm{~cm}$ proximal to the anal sphincter. After the administration of TNBS, the rats were held upsidedown (Trandelenburg position) position for a minute to preclude immediate anal leakage of the instillate. The rats were put into their metabolic cages again and had free access to food and water consumption.

\section{Experimental protocol}

We randomly divided the rats into six groups (Table 2) before the administration of TNBS to investigate the effectiveness of MEL loaded NPs. Each group included eight rats. In Group A, $0.6 \mathrm{ml}$ of $0.9 \%$ saline was given instead of TNBS, and no colitis was induced.

\section{Treatment protocol}

In the administration of the formulations to the rats, the circadian rhythms of the rats were taken into consideration due to the presence of MEL in the NP formulation. Therefore, the colitis was inducted at $10 \mathrm{am}$, and the NP formulations were administered at 4 pm. The treatment was continued by four consecutive days, and the animals were sacrificed at the fifth day. Considering the volume of the large intestine of the rats and the maximum amount of water a rat can drink at once, the oral and intracolonic administrations were designed as a volume of $1 \mathrm{ml}$. Eight $\mathrm{cm}$ long, thick, sterile stainless-steel gavage was used in intracolonic administration while six cm long, thin, sterile stainless steel gavage was used in oral administration. Rats were treated with $10 \mathrm{mg} / \mathrm{kg}$ of MEL loaded NP formulation [12][36].

\section{Preparation of the colonic tissue samples}

All the animals were sacrificed on the $5^{\text {th }}$ day. After opening their abdomen, the whole colon was removed. Thereafter, the rat colon was opened by longitudinal axis. Isotonic saline was used to clean the fecal content of the colon softly. Wet weight (mg) of the whole colon, lenght of the occured colonic ulcer $(\mathrm{cm})$, and rat weight/colon weight $(\mathrm{mg} / \mathrm{mg})$ ratio were recorded for each rat.

A visible appearance scoring system [40] shown in Table 3 was used to measure the severity of the colonic damage macroscopically. $10 \mathrm{~cm}$ of colon was separated into three parts. The first $4 \mathrm{~cm}$ part, which is close to the rectum, and the later two parts of $2 \mathrm{~cm}$ were used in the biochemical, immunological and histological investigations, respectively. After the sacrification of the rats, the colonic tissue samples were taken immediately into eppendorf tubes and kept at $-80^{\circ} \mathrm{C}$ until analyzed.

\section{Measurement of the oxidative stress on colonic mucosa}

In order to evaluate the oxidative stress in colonic mucosa; NOx, MDA and GSH levels were measured. The obtained results of the colitis and treatment groups were statistically compared.

\section{Determination of the NOx levels}

Griess reaction was used to determine NOx concentrations of rat tissue samples [41]. After the homogenization of $200 \mathrm{mg}$ colon sample in $0.1 \mathrm{M}$ phosphate buffer, a centrifugation was performed for a quarter hour at $3500 \mathrm{rpm}$. In order to reduce nitrate to nitrite, the same volume of vanadium (III) chloride was added to the $200 \mu$ of supernatant. The mixture was incubated at $37^{\circ} \mathrm{C}$ for $30 \mathrm{~min}$. After adding the same volumes of Griess I ( $0.2 \%$ naphthalene diethylamine dihydrochloride) and Griess II ( $2 \%$ sulphanilamide in $10 \%$ phosphoric acid) reactant, the mixture was incubated at $37^{\circ} \mathrm{C}$ for 10 min this time. Spectrophotometric assay method was used to measure the absorbance of the colon samples at $540 \mathrm{~nm}$.

\section{Determination of the MDA levels}

After the homogenization of $200 \mathrm{mg}$ colon sample in $10 \%$ trichloroacetic acid (1:9), a centrifugation was performed for twenty minutes at $4000 \mathrm{rpm}$. 750 $\mu \mathrm{L}$ of supernatant was mixed with the same volume of the solution of $1 \%$ butyl hydroxyl toluene in $\mathrm{EtOH}$ and $0.67 \%$ thiobarbituric acid. A water bath was used to boil the mixture. Spectrophotometric method was used to measure the absorbance of the colon samples at $532 \mathrm{~nm}$ [42].

\section{Determination of the GSH levels}

After the homogenization of $200 \mathrm{mg}$ colon sample in $10 \%$ trichloroacetic acid (1:9) at 2-8 $\mathrm{C}$, the centrifugation was performed for twenty minutes at 4000 rpm. $250 \mu \mathrm{L}$ of supernatant was mixed with the same volume of $\mathrm{Na}_{2} \mathrm{HPO}_{4} \cdot 2 \mathrm{H}_{2} \mathrm{O}$ and the Ellman's Reagent (5,5-dithio-bis-(2-nitrobenzoic acid) solutions (0.4 $\mathrm{mg} / \mathrm{mL}$ in $1 \%$ sodium citrate). Spectrophotometric method was used to measure the absorbance of the colon samples at $412 \mathrm{~nm}$ instantly [43].

\section{Immunological studies on colonic mucosa}

An immunoassay enzyme kit [rat TNF-a, IL-10 and IL-17 ELISA; eBIOSCIENCE®, Vienna, Austria] was used to analyze the rat colonic cytokine (TNF-a, IL-10, and IL-17) concentrations. After the homogenization of $200 \mathrm{mg}$ colon sample in $0.1 \mathrm{M}$ phosphate buffer, a centrifugation was performed for a quarter hour at $3500 \mathrm{rpm}$. Supernatants were passed through membrane filters $(0.45 \mu \mathrm{m})$ to avoid the interferance of cellular debris or particles. All the colonic samples were measured three times. 
Colonic mucosal tissues to be used in light microscope studies were fixed in 10\% formalin. EtOH was used to dehydrate the tissue samples. After clarification with xylene, the samples were embedded in paraffin blocks for histological investigation. Then each paraffin block was sliced with $4 \mu \mathrm{m}$ thickness. Xylene was used again for deparaffining the colon samples. Masson tricrom was used to stain after the rehydratation of the rat samples.

\section{Statistical analysis}

SPSS ${ }^{\circledR}$ for Windows 16.0 (Pad Software, San Diego, CA, USA) was used to perform statistical analysis. The entire data of this study was put into words as mean \pm confidence interval $(\mathrm{Cl})$. Values of $\mathrm{p}<0.05$ were considered as significant, and $\mathrm{P}<0.001$ was considered as very significant.

\section{Results And Discussion}

\section{In vitro Studies}

Colon is a very appropriate organ to target different kinds of drugs because of the enormous amount of enzymes of the bacterial flora, longer transit time compared to stomach, a pH, which is very closer to neutral, and lack of digestive enzymes. Many different systems were designed based on these unique features to deliver different drugs to the colon. The degradation of natural polymers, especially polysaccharides, by bacterial enzymes is the most appropriate colonic design method [44][45]. Negligible drug release is observed until the designed system reaches the gut and contacts with digestive enzymes. Pectin stands out among many biopolymers due to its low price, sensitivity to bacterial enzymes, and its wide variety.

Many different types of pharmaceutical forms including micro and nanoparticulate systems have been designed to carry drugs especially to the colon. These particulate drug carrier systems show better performance compared to conventional single unit dosage forms as they spread out when they reach the colon and form a large surface area where the bacterial enzymes can easily act [20]. As expected, an effective targeted drug release can occur in gut. Pectin has all the required properties to be used as a polymer in drug delivery systems targeted to the colon; it is biocompatible, biodegradable, non-toxic, and easily processed. The design strategy of the MEL loaded pectinate NPs started from the steady gelation ability of pectin with divalent cations. Pectin molecule has many carboxyl groups which are charged negatively. When these negatively charged ions come across with oppositely charged divalent cations $\left(\mathrm{CaCl}_{2}\right)$, intermolecular cross-links are formed by an electrostatic complexation interaction [46]. The characterization results of the optimal NP formulation are given in Table 4. We proved that calcium pectinate NPs with a diameter of less than $0.1 \mu$ m can be produced with a modified ionotropic gelation method. Neither complex equipment nor toxic organic solvent was used in this method.

Our pectin-based NPs had a negative surface electrical charge $(-24.24 \pm 1.03 \mathrm{mV})$ and a high bioaccumulation depending on the size (75.3 $\pm 3.3 \mathrm{~nm})$ in the ulcerated area The low polydispersity index indicated the narrow particle size distribution. The pH value of the prepared NP formulation was found to be $6.8 \pm 0.2$, and it was assumed suitable for the colonic administration.

The near and far images of NPs are depicted in Figure 2. When the nanoparticle images which we obtained using TEM were examined, it was observed that the nanoparticles were spherical, did not tend to agglomerate, and the average particle size values detected were in accordance with the average particle size values determined using the Zeta Nanosizer.

In the present study, after the preperation of the aqueous solution of pectin, the MEL was added into this solution and dispersed homogenously. At the final step of forming NPs, a counterion solution of calcium was added dropwise by 30 gauge micro needle. The MEL was entrapped very easily into the gelled NPs by sudden electro complexation occured between pectin and calcium. A high percentage of MEL entrapment $(94,4 \pm 0,3 \%$.) was detected due to hydrophobic properties of the MEL.

The detected unbound $\mathrm{Ca}^{+2}$ value in the NP formulation is $0.5 \pm 0.1 \mu \mathrm{g} / \mathrm{mL}$. This residual value of $\mathrm{Ca}^{+2}$ was less than the initial amount of $\mathrm{Ca}^{+2}(0.1 \%)$, which was used to produce the NP formulation.

IBD holds different regions of gastrointestinal tract out of stomach. It is expected that designed system does not release MEL in stomach but transport MEL to the site of inflammation (small and large intestine) successfully. Limited amount of MEL reache to colon as site of action after being administered by oral route, due to first pass metabolization effect of liver. However, the administration of MEL in designed microbiological enzymecontrolled colon specific drug delivery system prevent the metabolization of MEL successfully, and a potent level of MEL obtained to protect colonic injury.

A modified experimental technique was used for the in vitro release study of the MEL from the NP formulations, which was obtained from a previously published method [47]. Modified rotary basket method is more useful than other methods in the investigation of release profile of a particulate drug carrier system. In this manner, the impact of the changes made in the formulations is expressed better. In in vivo conditions, colon-specific drug delivery system will pass through the different $\mathrm{pH}$ values of gastrointestinal tract by different transit times, respectively, until it reaches the site of action. Due to the release of $\mathrm{HCl}$, gastric $\mathrm{pH}$ is very low (pH 1.2). In the small intestine, $\mathrm{pH}$ is near neutral (pH 7.4). Colonic $\mathrm{pH}$ is decreased to 6.8 due to fermentation of carbohydrates by anaerobic bacterias, which live in the large intestine. Therefore, to simulate the GI conditions, the MEL release from the NP formulation was tested in which the release medium was replaced at appropriate time intervals.

Pectin is a biopolymer which is degraded by the gut microflora. Cross-linking of pectin with Ca ions increased the stability in acidic and neutral pH medium Therefore, Ca pectinate was used as a colon-specific drug delivery system because it was low water-soluble but easily and completely broken by gut microflora [48][49]. The MEL release profiles from the NP formulation are depicted in Figure 1. According to the results of release studies conducted at consecutive media, $3.3 \pm 0.5 \%$ and $34.9 \pm 2.5 \%$ cumulative MEL release was obtained in stomach and until reaching large intestine, respectively, and at the end of the eighth hour $71.5 \pm 0.1 \%$ MEL (release in large intestine) released. When $2 \% \mathrm{v} / \mathrm{v}$ pectinex was added to the medium at the end of the fifth hour, 
there was no MEL residue in the prepared NP formulation. An optimal colon specific drug carrier system should not release more than one tenth of initial entrapped amount of drug. Thus, all remaining amount of MEL in the NP formulation was released in the colon due to the bacterial enzyme degredation of pectin. The release of MEL from the pectin nanoparticles was suppressed in the acidic medium. On the other hand, the addition of pectinase increased the MEL release. The developed NP formulation exhibited a succesful colon specific release of drug.

The main release kinetic characteristics of the NP formulations are shown in Table 5. In accordance with $r^{2}$ values of equations, the MEL release fitted with the Higuchi model properly. Thus, the MEL release from the NPs is controlled by diffusion [50] due to inert and porous structure of cross-linked calcium pectinate NPs matrix [51].

The ability of the NP formulation to adhere to the colonic mucosa of healthy and TNBS-induced colitis rats was measured by mucoadhesion tests. (Figure 3). Maximum detachment force (Fmax), work of adhesion (Wad) and work of mucoadhesion (Wmucoad) values were investigated. The designed NP formulation exhibited very good mucoadhesive property on the TNBS induced colitis colonic mucosa compared to healthy colonic mucosa ( $p<0.001)$. The NP formulation was 40 times more adherent to the inflamed colon mucosa $\left(0.441 \pm 0.012 \mathrm{mj} / \mathrm{cm}^{2}\right)$ than the healthy colon mucosa $\left(0,010 \pm 0,001 \mathrm{mj} / \mathrm{cm}{ }^{2}\right)$ (Table 6). These mucoadhesion, electrostatic interaction, and cumulation features extend the retention time of particles at site of action, and the MEL was released for a much longer time. Hereby, the healing and protective effects of MEL were enhanced.

The results of the stability studies of the NP formulation in three different test conditions are shown in Table 7. The stability studies were performed at $25^{\circ} \mathrm{C} / 60 \%$ relative humidity and $4^{\circ} \mathrm{C} /$ ambient humidity conditions for six months and $40{ }^{\circ} \mathrm{C} / 75 \%$ relative humidity conditions for three months. There were no statistically significant changes at PS, PDI, ZP, $\mathrm{pH}$, and MEL assay values ( $>0.05)$. However, at the end of the studies which were performed at 40 ${ }^{\circ} \mathrm{C} / 75 \%$ relative humidity conditions, $\mathrm{PS}, \mathrm{PDI}, \mathrm{ZP}, \mathrm{pH}$ and MEL assay values were statistically different from the initial values ( $\left.\mathrm{t}=0\right)$ ( $\left.\mathrm{p}<0.05\right)$. According to these results, the planned stability of the MEL loaded NPs was achieved.

According to all the results obtained from in vitro studies, the designed NPs were appropriate for oral and IC administration in the TNBS induced colitis rats. Moreover, it was assumed that this formulation was also appropriate in terms of stability. Therefore, further in vivo studies were performed.

\section{In vivo studies}

Recently, an increased interest has been observed in the investigation of the effect of different drugs used for the treatment of IBD. In order to understand how drugs affect the colitis, which is seen in IBD, chemical induced animal models are commonly used. An appropriate animal model of colitis should be histopathologically and clinically similar to IBD in humans. Similar morphological and pathological changes should occur in the gut of the animal.

Intracolonic administration of TNBS mixed with ethanol acting as "barrier breaker" is known as one of the most common methods to investigate IBD conditions in animal models. Moreover, colitis induced by TNBS is well clarified. This animal model is histopathologically and clinically very similar to IBD in humans [25][52]. First of all, EtOH destroyed the mucosal entirety as a barrier breaker, then TNBS adhered to colonic proteins, and turned them into immunogenic compounds. Macrofages recognized these new compounds as foreign, and this unusual situation was presented rapidly to T-lymphocytes. Thus, severe colonic inflammatory reactions started as a result of the attack of the immune system. For this reason, the TNBS was used in our study to investigate the acute and chronic histopathological changes occured in the rats, which are very similar to human IBD. The TNBS-induced colitis characterised by symptoms like bloody diarrhea, serious weight loss, increased the levels of daily water intake, and decreased the levels of daily food intake resulted in a common inflammation in the colonic mucosa.

MEL as a prophylactic agent may be administrated to rats before colitis induction to prevent colonic mucosal injury. Tahan et al. [8] administrated 100 $\mathrm{mg} / \mathrm{kg}$ MEL via IP route to rats 5 minutes after IC administration of acetic acid. In the present study, $10 \mathrm{mg} / \mathrm{kg}$ MEL was administered via IC and oral route to the rats 6 hours after the colitis induction with the TNBS.

\section{The effect of MEL treatment on weight change, food and water consumption and colon properties of rats}

According to metabolic cage findings (Figure 4a-c), percentage of the weight loss of the MEL treated rats with oral and intracolonic administration was significantly less than that of colitis and untreated group over the first 4 days after the induction of the colitis ( $p<0.001)$. However, the difference between the MEL treated rats and control group was insignificant $(p>0.05)$. The rats in the colitis group and treated with blank NP formulation consumed the pellets less than the MEL treated and control group over the first 4 days after the induction of the colitis $(p<0.001)$. In addition, the difference between the MEL treated and control group was insignificant ( $p>0.05)$. These results are attiributed to the loss of appetite in the rats due to the colitis induction by the TNBS. Additionally, water intake in the colitis group and groups treated with blank NP was significantly high due to the normalization of the common inflammation in colon, in comparison with control and the MEL treated groups ( $\mathrm{p}<0.001)$. The difference in water consumption between the MEL treated and control group was insignificant ( $p>0.05$ ). During the first 4 days subsequent to the induction of the colitis, the colitis group and groups treated with blank NP showed a significant increase in the diarrhea index (diarrhea was seen in all of the rats of each group), in comparison with control group. In the MEL treated groups (two rats in orally treated group, three rats in intracolonically treated group), there was a significant reduction observed in diarrhea index compared to blank NP treated groups. No bloody diarrhea was observed during the experiments in control and MEL treated groups. On the other hand, bloody diarrhea was seen in all rats except one in the group that was treated orally with blank NP formulation and in all rats in the colitis group and the group that was treated intracolonically with blank NP formulation. As seen from the results, the MEL loaded NP treatment alleviated the colitis symptoms independently of the administration route of the formulation. In brief, the frequent symptoms of IBD in human, just as \% weight loss, decreased the total food intake due to appetite loss, and increased water intake because increased inflammatory and bloody diarrhea were seen similarly in the colitis and blank NP treated groups. Moreover, there was a parallelism between control and MEL loaded NP treated groups.

Page $7 / 19$ 
The macroscobic appearance of the rat colons is shown in Figure 5. The wall of colon was dramatically thickened in the colitis group and groups treated with blank NPs. The thickened inflammed edematous mucosa enclosed the linear ulcerated regions and seemed to down-develop into the serosal layers. Macroscopic changes occurring in the rats completely match with the clinic profile of IBD [43]. The score of macroscopic damage was observed as $8.2 \pm 0.5$ in the colitis group, which was exposed to TNBS only. Treatment of MEL decreased this score by $73.2 \%$ and $67.1 \%$ in oral and intracolonic route, respectively.

If we evaluate the Figure 6, it is obviously seen that MEL significantly improved the TNBS-induced colonic tissue damage in contrast to blank NP treated groups $(\mathrm{p}<0.001)$. The inflammation induced increase in colonic weight, and colon weight/rat weight ratio were also reduced by the MEL treatment, in comparison with the colitis group and groups treated with blank NP $(p<0.001)$ (Figure 6a). The MEL treatment decreased the severity of mucosal damage and minimized the length of the ulcerated lesion regardless of the route of administration (Figure $6 \mathrm{~b}$ ). There was no ulcer lesion observed in the orally treated MEL loaded NP group just like the control group. Additionaly, a very small ulcer lesion $(0.3 \pm 0.5 \mathrm{~cm})$ was observed in group D, which was treated intracolonically. The treatment with blank NP formulation did not affect any healing progress on both administration routes (group E and F) (Figure 6c).

The increased colon weight seen in the colitis and blank NP treated groups was considered due to the thickening of the epithelium of the colonic epithelial cells that were exposed to TNBS as a defensive mechanism (Figure 6d). Besides, severe transmural inflammation, diffuse necrosis, inflammatory granulomas, ulceration, and submucosal infiltration of neutrophils increase the weight of colon. After sacrificing the rats, the colon tissue samples were taken immediately for macroscopic evaluation; lesions in the colon were scored with Wallace Scale for its widespread use in scientific research in accordance with international standards. There was a very mild inflammation in the colonic mucosa in groups $\mathrm{C}$ and $\mathrm{D}$ compared to group $\mathrm{B}$, $\mathrm{E}$ and $\mathrm{F}$ $(p<0.001)$. When we evaluate in vivo experiments and observations, it can be said that interference in the colon via a canula can create an additional stress effect, and it is more invasive compared to oral administration. While administrating the MEL loaded NP formulation to the rats with a canula, the integrity of the tissues was excessively disrupted. Furthermore, some anesthetic drugs were given by intraperitoneal route before the MEL administration to the rats additionally in group D. These two situations caused additional stress, and oxidative stress increased immediately. Consequently, the use of MEL by these cells significantly decreased, and the protective effect of MEL could not be observed compared to group $\mathrm{C}$ which was treated by orally ( $\mathrm{p}<0.05$ ). Oral and intracolonic administration of the MEL loaded NP formulation to the rats prevented ulcer formation by neutralizing the increased reactive oxygen species due to leukocyte infiltration in the submucosal and mucosal area of colon tissue.

\section{The effect of MEL treatment on colonic mucosal oxidative stress parameters}

MEL's performance on oxidative stress parameters was investigated to clarify the antioxidant effects in rats with TNBS induced colitis. For this purpose, the NOx levels (latest stable product of reactive nitrogen species), MDA levels (lipid peroxidation's latest stabil product) and GSH levels (a powerful endogenous antioxidant) were measured. Inflammation of colon is also related with the elevated levels of NOx as a reactive nitrogen species (ROS) due to the stimulated activity of inducible nitric oxide synthase (iNOS) in immune related cells like fibroblasts, macrophages, and neutrophils [5]. High levels of NOx aggravated the colonic inflammatory and damage. In addition, MDA is commonly used as an indicator of oxidative stress in colitis [11]. High levels of MDA in rectal biopsy samples of IBD patients are consistent evidences of the colonic damage, which is made by reactive species [52]. Reactive species mediated tissue injury is also protected by GSH, which is a powerful endogenous antioxidant. GSH deficiency in tissues is one of the major pathophysiological causes of injuries [53].Table 8 shows the MDA, NOx, and GSH levels of the colonic mucosa of all rats. High levels of MDA and NOx, and low levels of GSH in tissues indicate an elevated oxidative stress in tissues. Not surprisingly, the elevated NOx and MDA levels and accompanied reduced GSH levels were found in the colitis group due to the TNBS administration. The NOx levels elevated strikingly in the colitis group $(13.5 \pm 0.3 \mu \mathrm{mol} / \mathrm{g}) \mathrm{compared}$ to control group $(2.92 \pm 0.23 \mu \mathrm{mol} / \mathrm{g})$. High levels of NOx are strongly thought to be the major trigger factor of IBD. Elevated NOx levels are accompanied by high MDA levels due to severe peroxidation of membrane lipids. The aggravation of colonic inflammation is intimately related with elevated reactive oxygen species (ROS) generation and activation of immune related cells. The MEL reinstated the normal MDA levels by preventing lipid peroxidation. Theelevated NOx and MDA levels in the colitis group were reduced by the MEL treatment independently of the administration route, and the colonic mucosal oxidative injury was effectively inhibited. Additionally, significantly reduced GSH (a key antioxidant in the colon) levels were found in the colitis group compared to control and MEL treated groups. The MEL treatment elevated the low levels of GSH due to the augmentation of the antioxidant capacity in colonic tissue. The MEL, which has direct and indirect strong antioxidant properties, inhibited the development of colonic damage in the rats after the TNBS exposure. This is the greatest proof of increased levels of reactive species, which are closely related to the pathophysiology of colitis. There were no significant differences among the levels of NOx, MDA and GSH in Group A, C and D ( $>0.05)$. Our results showed that the MEL treatment decreased the colonic NOx and MDA levels and increased the levels of GSH compared to blank NP treatment $(p<0.001)$. The difference between Group B, Group E and Group F in terms of MDA, NOx and GSH levels of colon tissues was also insignificant ( $p>0.05)$. It means that neither intracolonic nor oral blank NP formulation treatment affected the MDA, NOx, and GSH levels of colon tissues.

\section{The effect of MEL treatment on inflammatory parameters}

A wide variety of toxic free radicals was effectively scavenged by the MEL and its active metabolites. Besides, the MEL enhanced the activity of antioxidant enzymes. MEL successfully fulfills its direct and indirect antioxidant functions by preventing the lipid peroxidation of cell membrane [54][55]. Improvement of colonic inflammation by MEL, which is a powerful antioxidant, indicates that free radicals have an important role in the pathophysiology of colitis. When the studies examined in which the effects of MEL is evaluated by chemicals induced colitis on experimental animal models, the treatment dose of MEL and the duration of treatment vary widely. Nevertheless, these studies are the consistent evidences of antiinflammatory and antioxidant effects of MEL

treatment in IBD [8][9][10][11][12]. 
The elevated TNF-a, IL-10, and, IL-17 levels were found in the colitis group and blank NP treated groups compared to control and MEL treated groups $(p<0.001)$ (Table 8). Blank NP treatment exerted no effect by itself on the cytokine production in colonic tissues. The MEL therapy, regardless of the administration route, decreased the cytokine production and regulated the inflammatory process after the TNBS administration to the rats. There was no significant difference detected in colonic TNF-a values between control and MEL treated groups ( $p>0.05$ ). In groups A, C and D, IL-10 and IL-17 levels were lower than the detection limit of the ELISA kit $(p>0.05)$.

Another important target in the treatment of inflammatory colonic diseases is the regulation of immune-associated cells. Throughout the inflammation of colon, a wide variety of cytokines is excreted with directly local and/or systemic effects. The inflammation of colon is initiated and aggravated by cytokines.

Cytokines are highly necessary parts of immune system which provide healthy colonic homeostasis. Enhanced production of proinflammatory cytokines and / or reduced antiinflammatory cytokine production are important in the development of different inflammatory diseases such as IBD. TNF-a is a major cytokine with its powerful inflammatory characteristics in IBD. It plays a key role in cell communication on apoptotic pathways in colon which cause sudden cell death, survival and rapid proliferation of immune related cells. In addition, it has pleiotropic effects which enhance the overproduction of adhesion molecules in colonic tissue [56]. IL-17, a key mediator of immune-inflammatory reactions, increases chemokine production, leading to recruitment of monocytes and especially neutrophils to sites of inflammation [57]. IL-10 is regarded as an antiinflammatory cytokine by decreasing the secretion of proinflammatory cytokines and antigen presentation and hence the activation of lymphocytes. Thus, it compensates for the increased immune response in the colonic mucosa [58]. It is known that a high level of TNF-a and IL-17 in colonic tissues show an increase of inflammation in colon due to TNBS administration.

Cellular disintegrity caused by TNBS and the following acute inflammatory response acts on local non-specific immune cells and exacerbates the inflammatory process. Increase in cellular adhesion molecules of vascular endothelial cells forms an adhesion site for circulating neutrophils. TNF-a is a major cytokine with inflammatory characteristics, secreted by various non-specific immune cells and acting systemically. IL-17 family of cytokines is a marker cytokine for the Th17 lineage of lymphocytes. Th17 cells are usually the first subset to be generated, especially in response to extracellular bacteria and are the main effector cells in the mucosae. With IL-17, more and more neutrophils are recruited to inflammed sites. In our model, TNF-a together with IL17 increased drastically in the TNBS without MEL groups (groups B, E, and F).

As a response, tissue IL-10 levels increased immediately to regulate the increased inflammation. The MEL loaded NP treatment (in group C and D) administration route independently inhibited the proinflammatory cytokines (TNF-a and IL-17). Dampening of the inflammatory mediators increases the reinforcement of immune related cells to the ulcerated colonic regions [59]. The generation of bioadhesive molecules, which support the cohesion of neutrophils to endothelial cells, is inhibited. As a result, MEL reduces transmigration of the endothelial cells and oedema, which conduce to colonic injury.

\section{The Effect of MEL treatment on macroscopic scoring and microscopic colon histology}

Severe damage of surface epithelium increased the inflammatory cell infiltration, degeneration of crypts, erosion of lamina propria, distortion of intestinal crypt and mucosa and submucosal edema were observed in the colitis group (Figure 7). In contrast, an improvement in the inflammation was found, and the degeneration of crypts and edema disappeared in the MEL treated groups. Regular colon mucosa and submucosa were observed again, similar to control group. The increased inflammatory cell infiltration turned back to normal (Group C, D Figure 7). In the comparision of MEL treatment groups, the tissue healing was determined to be less effective in the IC administration against oral administration. In groups $E$ and $F$, no apparent tissue healing was observed. Similar findings for the colitis group were determined in these blank NP treated groups. Severe damage of surface epithelium, erosion of lamina propria, degeneration of crypts, and elevated inflammatory cell infiltration were observed again, as in the colitis group. However, it was seen that the colonic damage occured in blank NP treated group via IC route was more severe than oral route. Histological investigations concluded that the epitelization of the colon tissues in MEL administered groups was much better than that of the untreated groups (Group B, E and F). Improvement in the structure of the intestinal crypt and inflammation, and disappearance of edema were observed to be the same in groups, which were treated orally with the MEL loaded NP formulation (Group C) and given intracolonic treatment (Group D). the colonic structure was observed normal, as in the control grup. Integrity of the crypts tissue and colonic mucosal epithelium was protected. The MEL treatment kept the tissue damage at a minimum level. Oral treatment with the MEL loaded NP was observed to be more succesful than IC route.

Therefore, in this research, influential impacts of the MEL were proven as a recognized strong antioxidant and antiinflammatory agent. The MEL treatment reduced the elevated levels of NOx, MDA, TNF-a, IL-10 and IL-17 in the rat colitis significantly. In addition, the elevated GSH concentrations were obtained. The enhanced production of ROS and NOS and the oversecretion of cytokines, which launch and regulate the colonic inflammation, were supposed to be major causes of IBD. Therefore, the most important focal point of IBD therapy is preventing colonic inflammation being triggered by mediators like TNF-a and ROS. MEL treatment protected the normal colonic mucosal structure in the rats effectively.

\section{Conclusion}

In this study, the MEL loaded pectin NPs ameliorated the TNBS-induced IBD in the rats evidently. A meaningful decrease was observed in the colonic fibrosis, oxidative stress, and inflammatory parameters of colon accompanying histologic injury.

The rapid hepatic metabolization of MEL by oral administration led to a restricted amount of drug in the inflamed colonic area. It is impressive to cite that the MEL entrapped NPs therapy was very efficacious in this animal model of IBD, due to its strong bioadhesive properties, superficial negative electrical 
charge, and high bioaccumulation ability in the inflammatory cells because of its nano size. The designed NP system was anticipated to stay in the inflamed colonic mucosa and to release the MEL in the site of action throughout comparatively extended time, which increases the dual impacts of MEL.

With the results of this study, it can be supposed that MEL nanoparticles can be a very effective alternative for the treatment and handling of IBD and for the amelioration of subsequent colonic damage by regulating the various mechanisms involved in IBD pathophysiology. Further studies with MEL loaded nanomedicines alone or combining with well-established drugs in IBD may ensure a basic principle for its practical use as an alternative agent due to its low toxicity. In the near future, this approach may lead to an ideal IBD treatment strategy.

\section{Abbreviations}

IBD: Inflammatory Bowel Disease

MEL: Melatonin

TNF- a: Tumor necrosis factor alpha

IL: Interleukin

TNBS: 2,4,6-Trinitrobenzenesulfonic acid

NP: Nanoparticle

IC: Intrecolonic

IP: Intraperitoneal

NOx: Nitric oxide

MDA: Malondialdehyde

GSH: Glutathione

PS: Particle size

ZP: Zeta potential

\section{Declarations}

\section{Ethics approval and consent to participate}

In vivo studies were carried out in Gazi University-Laboratory Animals Raising and Experimental Researches Center with the permission and number of G.U. ET-12.026 of Gazi University Local Ethics Committee for Animal Experiments, within the framework of ethical committee rules. The consent to participate does not apply to this study.

\section{Consent for publication}

All the authors are aware of and accept for the submission of this original research article to Drug Delivery and Translational Research.

\section{Availability of data and materials}

The datasets generated during and/or analysed during the current study are available from the corresponding author on reasonable request.

\section{Competing interests}

No potential conflict of interest was reported by the authors.

\section{Funding}

This study was supported by Gazi University, Projects of Scientific Investigation under the project number: 02/2012-40.

\section{Authors' contributions}

S. Yener performed the in vitro/in vivo experiments and wrote the manuscript draft. K.G.Akbulut performed the in vivo experiments and biochemical analysis. Immunological studies were carried out by R.Karakuş. D. Erdoğan performed the histological evaluations. The initial idea of the article was developed by F. Acartürk, who performed the literature search and provided resources and supervised the project. The manuscript was edited through contributions of all authors. 
We would like to thank CP Kelco (Denmark) for their generous donation of pectin.

\section{References}

1. Engel MA and Neurath MF. New pathophysiological insights and modern treatment of IBD. Journal of Gastroenterology 2010; 45: 571-83. DOI: https://doi.org/10.1007/s00535-010-0219-3

2. Sartor RB. Mechanisms of disease: Pathogenesis of Crohn's disease and ulcerative colitis. Nature Clinical Practice Gastroenterology and Hepatology 2006; 3: 390-407. DOI: https://doi.org/10.1038/ncpgasthep0528

3. Jena G, Trivedi PP, and Sandala B. Oxidative stress in ulcerative colitis: An old concept but a new concern. Free Radical Research 2012; 46: 1339-45. DOI: https://doi.org/10.3109/10715762.2012.717692

4. Kruidenier L and Verspaget HW. Antioxidants and mucosa protectives: Realistic therapeutic options in inflammatory bowel disease? Mediators of Inflammation 1998; 162: 157-62. DOI: https://doi.org/10.1080/09629359891081

5. Zingarelli B, Szabó C, and Salzman AL. Reduced oxidative and nitrosative damage in murine experimental colitis in the absence of inducible nitric oxide synthase. Gut 1999; 45: 199-209. DOI: https://doi.org/10.1136/gut.45.2.199

6. Bubenik GA. Localization, physiological significance and possible clinical implication of gastrointestinal melatonin. NeuroSignals 2001; 10 : $350-66$. DOI: https://doi.org/10.1159/000046903

7. Reiter RJ. Melatonin : clinical relevance. 2003; 17: 273-85. DOI: https://doi.org/10.1053/ybeem.2003.249

8. Tahan G, Gramignoli R, Marongiu F, Aktolga S, Cetinkaya A, Tahan V, et al. Melatonin expresses powerful anti-inflammatory and antioxidant activities resulting in complete improvement of acetic-acid-induced colitis in rats. Digestive Diseases and Sciences 2011; 56: 715-20. DOI: https://doi.org/10.1007/s10620-010-1364-5

9. Mei Q, Yu JP, Xu JM, Wei W, Xiang L, and Yue L. Melatonin reduces colon immunological injury in rats by regulating activity of macrophages. Acta Pharmacologica Sinica 2002; 10: 882-6.

10. Mei Q, Xu JM, Xiang L, Hu YM, Hu XP, and Xu ZW. Change of nitric oxide in experimental colitis and its inhibition by melatonin in vivo and in vitro. Postgraduate Medical Journal 2005; 81: 667-72. DOI: https://doi.org/10.1136/pgmj.2004.030817

11. Cuzzocrea S, Mazzon E, Serraino I, Lepore V, Terranova ML, Ciccolo A, et al. Melatonin reduces dinitrobenzene sulfonic acid-induced colitis. Journal of Pineal Research 2001; 30: 1-12. DOI: https://doi.org/10.1034/j.1600-079X.2001.300101.x

12. Necefli A, Tulumoğlu B, Giriş M, Barbaros U, Gündüz M, Olgaç V, et al. The effect of melatonin on TNBS-induced colitis. Digestive Diseases and Sciences 2006; 51: 1538-45. DOI: https://doi.org/10.1007/s10620-005-9047-3

13. Nosál'ová V, Zeman M, Černá S, Navarová J, and Zakálová M. Protective effect of melatonin in acetic acid induced colitis in rats. Journal of Pineal Research 2007; 42: 364-70. DOI: https://doi.org/10.1111/j.1600-079X.2007.00428.x

14. Mazzon E, Esposito E, Crisafulli C, Riccardi L, Muià C, Bella P Di, et al. Melatonin modulates signal transduction pathways and apoptosis in experimental colitis. Journal of Pineal Research 2006; 41: 363-73. DOI: https://doi.org/10.1111/j.1600-079X.2006.00378.x

15. Akcan A, Kucuk C, Sozuer E, Esel D, Akyildiz H, Akgun H, et al. Melatonin reduces bacterial translocation and apoptosis in trinitrobenzene sulphonic acid-induced colitis of rats. World Journal of Gastroenterology 2008; 14: 918-24. DOI: https://doi.org/10.3748/wjg.14.918

16. Marquez E, Sánchez-Fidalgo S, Calvo JR, La De Lastra CA, and Motilva V. Acutely administered melatonin is beneficial while chronic melatonin treatment aggravates the evolution of TNBS-induced colitis. Journal of Pineal Research 2006; 2: 48-55. DOI: https://doi.org/10.1111/j.1600079X.2005.00275.x

17. Li JH, Yu JP, Yu HG, Xu XM, Yu LL, Liu J, et al. Melatonin reduces inflammatory injury through inhibiting NF-k $\beta$ activation in rats with colitis. Mediators of Inflammation 2005; 2005: 185-93. DOI: https://doi.org/10.1155/MI.2005.185

18. Lautenschläger C, Schmidt C, Fischer D, and Stallmach A. Drug delivery strategies in the therapy of inflammatory bowel disease. Advanced Drug Delivery Reviews 2014; 71: 58-76. DOI: https://doi.org/10.1016/j.addr.2013.10.001

19. Ashford M, Fell J, Attwood D, Sharma H, and Woodhead P. An evaluation of pectin as a carrier for drug targeting to the colon. Journal of Controlled Release 1993; 26: 213-20. DOI: https://doi.org/10.1016/0168-3659(93)90188-B

20. Cheng K and Lim LY. Insulin-loaded calcium pectinate nanoparticles: Effects of pectin molecular weight and formulation pH. Drug Development and Industrial Pharmacy 2004; 30: 359-67. DOI: https://doi.org/10.1081/DDC-120030930

21. Sharma R, Ahuja M, and Kaur H. Thiolated pectin nanoparticles: Preparation, characterization and ex vivo corneal permeation study. Carbohydrate Polymers 2012; 87: 1606-10. DOI: https://doi.org/10.1016/j.carbpol.2011.09.065

22. Opanasopit $P$, Apirakaramwong A, Ngawhirunpat T, Rojanarata $T$, and Ruktanonchai U. Development and characterization of pectinate micro/nanoparticles for gene delivery. AAPS PharmSciTech 2008; 9: 67-74. DOI: https://doi.org/10.1208/s12249-007-9007-7

23. Nižić L, Potaś J, Winnicka K, Szekalska M, Erak I, Gretić M, et al. Development, characterisation and nasal deposition of melatonin-loaded pectin/hypromellose microspheres. European Journal of Pharmaceutical Sciences 2020; 141: 105-15. DOI:

https://doi.org/10.1016/j.ejps.2019.105115

24. Chami B, Martin NJJ, Dennis JM, and Witting PK. Myeloperoxidase in the inflamed colon: A novel target for treating inflammatory bowel disease. Archives of Biochemistry and Biophysics 2018; 645: 61-71. DOI: https://doi.org/10.1016/j.abb.2018.03.012 
25. Dvorak AM and Dickersin GR. Crohn's disease: transmission electron microscopic studies. I. Barrier function. Possible changes related to alterations of cell coat, mucous coat, epithelial cells, and Paneth cells. Human Pathology 1980; 11: 561-71.

26. Jubeh TT, Barenholz Y, and Rubinstein A. Differential adhesion of normal and inflamed rat colonic mucosa by charged liposomes. Pharmaceutical Research 2004; 21: 447-53. DOI: https://doi.org/10.1023/B:PHAM.0000019298.29561.cd

27. Collnot EM, Ali $\mathrm{H}$, and Lehr CM. Nano- and microparticulate drug carriers for targeting of the inflamed intestinal mucosa. Journal of Controlled Release 2012; 161: 235-46. DOI: https://doi.org/10.1016/j.jconrel.2012.01.028

28. Naeem M, Oshi MA, Kim J, Lee J, Cao J, Nurhasni H, et al. pH-triggered surface charge-reversal nanoparticles alleviate experimental murine colitis via selective accumulation in inflamed colon regions. Nanomedicine: Nanotechnology, Biology, and Medicine 2018; 14: 823-34. DOI:

https://doi.org/10.1016/j.nano.2018.01.003

29. Lamprecht A, Yamamoto $\mathrm{H}$, Takeuchi $\mathrm{H}$, and Kawashima Y. A pH-sensitive microsphere system for the colon delivery of tacrolimus containing nanoparticles. Journal of Controlled Release 2005; 104: 337-46. DOI: https://doi.org/10.1016/j.jconrel.2005.02.011

30. Davoudi Z, Peroutka-Bigus N, Bellaire B, Wannemuehler M, Barrett TA, Narasimhan B, et al. Intestinal organoids containing poly(lactic-co-glycolic acid) nanoparticles for the treatment of inflammatory bowel diseases. Journal of Biomedical Materials Research - Part A 2018; 106: 876-86. DOI: https://doi.org/10.1002/jbm.a.36305

31. Pertuit D, Moulari B, Betz T, Nadaradjane A, Neumann D, Ismaïli L, et al. 5-amino salicylic acid bound nanoparticles for the therapy of inflammatory bowel disease. Journal of Controlled Release 2007; 123: 211-8. DOI: https://doi.org/10.1016/j.jconrel.2007.08.008

32. Tabata Y and Ikada Y. Phagocytosis of polymer microspheres by macrophages. Advances in Polymer Science 1990; 107-41. DOI: https://doi.org/10.1007/bfb0043062

33. Acartürk F, Yener S, and Değim T. Development of pectin-based nanoparticles containing melatonin for the treatment of inflammatory bowel disease i. preparation and characterization studies. In: Development of pectin-based nanoparticles containing melatonin for the treatment of inflammatory bowel disease i. preparation and characterization studies. FIP Congr. PSWC, 2014.

34. Da Rocha Lindner G, Khalil NM, and Mainardes RM. Resveratrol-loaded polymeric nanoparticles: Validation of an HPLC-PDA method to determine the drug entrapment and evaluation of its antioxidant activity. The Scientific World Journal 2013; 2013. D0I: https://doi.org/10.1155/2013/506083

35. Jain AK and Thareja S. In vitro and in vivo characterization of pharmaceutical nanocarriers used for drug delivery. Artificial Cells, Nanomedicine and Biotechnology 2019; 524-39. DOI: https://doi.org/10.1080/21691401.2018.1561457

36. Esiringü F, Tuğcu-Demiröz F, Acartürk F, Coşkun Cevher Ş, Bircan F, and Sarı Kılıçaslan SM. Investigation of the effect of intracolonic melatonin gel formulation on acetic acid-induced colitis. Drug Delivery 2016; 23: 2318-26. DOI: https://doi.org/10.3109/10717544.2014.982773

37. Tuğcu-Demiröz F, Acartürk F, and Erdoğan D. Development of long-acting bioadhesive vaginal gels of oxybutynin: Formulation, in vitro and in vivo evaluations. International Journal of Pharmaceutics 2013; 457: 25-39. DOI: https://doi.org/10.1016/j.ijpharm.2013.09.003

38. Singh AK. Nanoparticle Pharmacokinetics and Toxicokinetics. In: Engineered Nanoparticles. , 2016. 229-93. DOI: https://doi.org/10.1016/b978-0-12801406-6.00006-6

39. Kietzmann D, Moulari B, Béduneau A, Pellequer Y, and Lamprecht A. Colonic delivery of carboxyfluorescein by $\mathrm{pH}$-sensitive microspheres in experimental colitis. European Journal of Pharmaceutics and Biopharmaceutics 2010; 76: 290-5. D0l: https://doi.org/10.1016/j.ejpb.2010.06.013

40. Wallace JL, MacNaughton WK, Morris GP, and Beck PL. Inhibition of leukotriene synthesis markedly accelerates healing in a rat model of inflammatory bowel disease. Gastroenterology 1989; 96: 29-36. DOI: https://doi.org/10.1016/0016-5085(89)90760-9

41. Miranda KM, Espey MG, and Wink DA. A rapid, simple spectrophotometric method for simultaneous detection of nitrate and nitrite. Nitric Oxide Biology and Chemistry 2001; 5: 62-71. DOI: https://doi.org/10.1006/niox.2000.0319

42. Casini AF, Ferrali M, Pompella A, Maellaro E, and Comporti M. Lipid peroxidation and cellular damage in extrahepatic tissues of bromobenzeneintoxicated mice. American Journal of Pathology 1986; 123: 520-31.

43. Aykaç G, Uysal M, Süha Yalçin A, Koçak-Toker N, Sivas A, and Öz H. The effect of chronic ethanol ingestion on hepatic lipid peroxide, glutathione, glutathione peroxidase and glutathione transferase in rats. Toxicology 1985; 36: 71-6. DOI: https://doi.org/10.1016/0300-483X(85)90008-3

44. Tuğcu-Demiröz F, Acartürk F, Takka S, and Konuş-Boyunağa Ö. In-vitro and in-vivo evaluation of mesalazine-guar gum matrix tablets for colonic drug delivery. Journal of Drug Targeting 2004; 12: 105-12. DOI: https://doi.org/10.1080/10611860410001693751

45. Celkan A, Acartürk F, Tu凶cu-Demiröz F, Gökçora N, Akkaş BE, and Güner LA. Gamma scintigraphic studies on guar gum-based compressed coated tablets for colonic delivery of theophylline in healthy volunteers. Journal of Drug Delivery Science and Technology 2016; 32: 31-7. D0I: https://doi.org/10.1016/j.jddst.2016.01.009

46. Grant GT, Morris ER, Rees DA, Smith PJC, and Thom D. Biological interactions between polysaccharides and divalent cations: The egg-box model. FEBS Letters 1973; 32: 195-8. DOI: https://doi.org/10.1016/0014-5793(73)80770-7

47. Khopade AJ and Jain NK. Long-circulating multiple-emulsion system for improved delivery of an anticancer agent. Drug Delivery: Journal of Delivery and Targeting of Therapeutic Agents 1999; 6: 107-10. DOI: https://doi.org/10.1080/107175499267020

48. Khotimchenko M. Pectin polymers for colon-targeted antitumor drug delivery. International Journal of Biological Macromolecules 2020; 158 : 1110-24. DOI: https://doi.org/10.1016/j.ijbiomac.2020.05.002

49. Lee SH, Bajracharya R, Min JY, Han JW, Park BJ, and Han HK. Strategic approaches for colon targeted drug delivery: An overview of recent advancements. Pharmaceutics 2020; 12. DOI: https://doi.org/10.3390/pharmaceutics12010068

Page 12/19 
50. Sriamornsak P and Nunthanid J. Calcium pectinate gel beads for controlled release drug delivery: I. Preparation and in vitro release studies. International Journal of Pharmaceutics 1998; 160: 207-12. DOI: https://doi.org/10.1016/S0378-5173(97)00310-4

51. Antoniou E, Margonis GA, Angelou A, Pikouli A, Argiri P, Karavokyros I, et al. The TNBS-induced colitis animal model: An overview. Annals of Medicine and Surgery 2016; 11: 9-15. DOI: https://doi.org/10.1016/j.amsu.2016.07.019

52. Motavallian-Naeini A, Andalib S, Rabbani M, Mahzouni P, Afsharipour M, and Minaiyan M. Validation and optimization of experimental colitis induction in rats using 2, 4, 6-trinitrobenzene sulfonic acid. Research in Pharmaceutical Sciences 2012; 7: 159-69.

53. Shan X, Aw TY, and Jones DP. Glutathione-dependent projection against oxidative injury. Pharmacology and Therapeutics 1990; 47: 61-71. DOI: https://doi.org/10.1016/0163-7258(90)90045-4

54. Rachmilewitz D, Stamler JS, Bachwich D, Karmeli F, Ackerman Z, and Podolsky DK. Enhanced colonic nitric oxide generation and nitric oxide synthase activity in ulcerative colitis and Crohn's disease. Gut 1995; 36: 718-23. DOI: https://doi.org/10.1136/gut.36.5.718

55. Grisham MB. Oxidants and free radicals in inflammatory bowel disease. The Lancet 1994; 344: 859-61. DOI: https://doi.org/10.1016/S01406736(94)92831-2

56. Baumann H and Gauldie J. The acute phase response. Immunology Today 1994; 15: 74-80. DOI: https://doi.org/10.1016/0167-5699(94)90137-6

57. Mangan PR, Harrington LE, O'Quinn DB, Helms WS, Bullard DC, Elson CO, et al. Transforming growth factor- $\beta$ induces development of the T H17 lineage. Nature 2006; 441: 231-4. DOI: https://doi.org/10.1038/nature04754

58. Paul G, Khare V, and Gasche C. Inflamed gut mucosa: Downstream of interleukin-10. European Journal of Clinical Investigation 2012; 42: 95-109. D0I: https://doi.org/10.1111/j.1365-2362.2011.02552.x

59. Mirbagheri SA, Nezami BG, Assa S, and Hajimahmoodi M. Rectal administration of d-alpha tocopherol for active ulcerative colitis: A preliminary report. World Journal of Gastroenterology 2008; 14: 5990-5. DOI: https://doi.org/10.3748/wjg.14.5990

\section{Tables}

Table 1. The formulation parameters of the optimum nanoparticle formulation

\begin{tabular}{|ll|}
\hline Pectin conc. & $\mathbf{0 . 0 5 \%}(\mathrm{w} / \mathrm{v})$ \\
\hline $\mathrm{CaCl}_{2}$ conc. & $0.5 \%(\mathrm{w} / \mathrm{v})$ \\
\hline Pectin:MEL ratio & $1: 1$ \\
Cross-linking time & $15 \mathrm{~min}$ \\
\hline Stirring rate & $10000 \mathrm{rpm}$ \\
\hline
\end{tabular}

Table 2. Design of in vivo experimental groups (Each group $n=8$ )

\begin{tabular}{|lll|}
\hline GROUP & Administration route & Administered formulation \\
\hline A (Sham group, $\mathbf{0 . 9} \% \mathrm{NaCl})$ & - & No Treatment \\
\hline B (TNBS- induced colitis group) & - & No Treatment \\
\hline C (Treatment group 1) & Oral & MEL $(10 \mathrm{mg} / \mathrm{kg})$ loaded NP formulation \\
D (Treatment group 2) & Intracolonic & MEL $(10 \mathrm{mg} / \mathrm{kg})$ loaded NP formulation \\
\hline E (Treatment control group 1) & Oral & Blank NP formulation \\
\hline F (Treatment control group 2) & Intracolonic & Blank NP formulation \\
\hline
\end{tabular}

Table 3. Criteria for assessment of macroscopic colonic damage

\begin{tabular}{|ll|}
\hline Score & Appearance \\
\hline $\mathbf{0}$ & Normal \\
\hline $\mathbf{1}$ & Localized hyperemia, no ulcers \\
\hline $\mathbf{3}$ & Ulceration without hyperemia \\
\hline $\mathbf{4}$ & Ulceration with inflammation at 1 site \\
\hline $\mathbf{5}$ & Major sites of damage extending $>1 \mathrm{~cm}$ along length of colon \\
\hline $6-10$ & When an area of damage extended $>2 \mathrm{~cm}$ along length of colon, score was increased by 1 for each additional cm of involvement \\
\hline
\end{tabular}

Page 13/19 
Table 4. The characterization properties of the optimal nanoparticle formulation

\begin{tabular}{|ll|}
\hline Mean particle size & $75.3 \pm 3.3 \mathrm{~nm}$ \\
\hline Zeta potential & $-24.24 \pm 1.03 \mathrm{mV}$ \\
\hline Polydispersity index & $0.109 \pm 0.067$ \\
\hline Released MEL at the end of $8 \mathrm{~h}$ & $84.0 \pm 0.7 \%$ \\
\hline
\end{tabular}

Table 5. Kinetic assessment of the release data of melatonin from NP formulation

\begin{tabular}{|lllllll|}
\hline Release kinetic & \multicolumn{2}{l}{ Zero order } & \multicolumn{2}{ll}{ First order } & Q $\sqrt{ }$ & \\
\hline Constant & $\mathbf{k}_{\mathbf{0}}$ & $\mathbf{r}^{2}$ & $\mathbf{k}_{1}$ & $\mathbf{r}^{2}$ & $\mathbf{k}$ & $\mathbf{r}^{2}$ \\
\hline NP formulation & 0.1506 & 0.9370 & 0.0034 & 0.8171 & 4.2716 & 0.9981 \\
\hline
\end{tabular}

$\mathrm{k}_{0}$ : zero-order release constant; $\mathrm{k}_{1}$ : first-order release constant; $\mathrm{k}$ : is therate constant obtained from the slope of the linear regression of cumulative amount release per unit area versus square root of time; $r^{2}$ :regression coefficient.

Table 6. Mucoadhesion values of the NP formulations using texture analyzer with rat colonic mucosa $(n=6)$.

\begin{tabular}{|llll|}
\hline & $F_{\max }$ & $W_{\mathrm{ad}}$ & $\mathrm{W}_{\text {mucoad }}$ \\
& $\mathbf{( N )}$ & $\mathbf{( N . m m )}$ & $\left(\mathbf{m J} / \mathrm{cm}^{2}\right)$ \\
\hline Healthy colonic mucosa & $0.043 \pm 0,003$ & $0.012 \pm 0.001$ & $0.010 \pm 0.001$ \\
\hline TNBS induced colitis colonic mucosa & $0.157 \pm 0.016$ & $0.541 \pm 0.014$ & $0.441 \pm 0.012$ \\
\hline
\end{tabular}

Table 7. The stability test results of the NP formulation at three different storage conditions. 


\begin{tabular}{|c|c|c|c|c|c|c|c|c|c|}
\hline $\begin{array}{l}\text { Time } \\
\text { (Week) }\end{array}$ & 0 & 1 & 2 & 4 & 8 & 12 & 16 & 20 & 24 \\
\hline \multicolumn{10}{|c|}{$25^{\circ} \mathrm{C} / 60 \%$ Relative humidity } \\
\hline $\begin{array}{l}\text { PS } \\
\text { (nm) }\end{array}$ & $75.5 \pm 0.4$ & $75.5 \pm 0.6$ & $75.3 \pm 0.9$ & $75.4 \pm 1.0$ & $75.3 \pm 1.1$ & $75.8 \pm 0.5$ & $75.7 \pm 0.2$ & $75.4 \pm 0.4$ & $75.7 \pm 0.7$ \\
\hline PDI & $0.112 \pm 0.008$ & $0.113 \pm 0.004$ & $0.112 \pm 0.007$ & $0.112 \pm 0.007$ & $0.112 \pm 0.010$ & $0.116 \pm 0.009$ & $0.112 \pm 0.008$ & $0.111 \pm 0.011$ & $0.115 \pm 0.010$ \\
\hline $\begin{array}{l}\mathrm{ZP} \\
(\mathrm{mV})\end{array}$ & $-24.30 \pm 0.45$ & $-24.31 \pm 1.74$ & $-24.38 \pm 1.84$ & $-24.29 \pm 2.15$ & $-24.27 \pm 0.44$ & $-24.25 \pm 2.55$ & $-24.30 \pm 2.62$ & $-24.27 \pm 0.26$ & $-24.35 \pm 2.00$ \\
\hline $\mathrm{pH}$ & $6.9 \pm 0.1$ & $6.8 \pm 0.1$ & $6.8 \pm 0.0$ & $6.8 \pm 0.2$ & $6.8 \pm 0.2$ & $6.8 \pm 0.2$ & $6.8 \pm 0.2$ & $6.7 \pm 0.1$ & $6.7 \pm 0.2$ \\
\hline $\begin{array}{l}\text { Assay } \\
\text { (\%) }\end{array}$ & $99.5 \pm 0.4$ & $99.4 \pm 1.8$ & $99.3 \pm 1.4$ & $99.3 \pm 1.7$ & $99.2 \pm 1.4$ & $99.7 \pm 0.1$ & $99.2 \pm 0.7$ & $99.3 \pm 1.2$ & $98.9 \pm 1.1$ \\
\hline \multicolumn{10}{|c|}{$40^{\circ} \mathrm{C} / 75 \%$ Relative humidity } \\
\hline $\begin{array}{l}\text { PS } \\
\text { (nm) }\end{array}$ & $75.6 \pm 0.8$ & $75.9 \pm 0.4$ & $75.8 \pm 1.0$ & $76.1 \pm 0.3$ & $75.7 \pm 0.3$ & $75.8 \pm 0.2$ & $83.9 \pm 0.4$ & $88.0 \pm 1.0$ & $89.7 \pm 0.4$ \\
\hline PDI & $0.110 \pm 0.003$ & $0.110 \pm 0.001$ & $0.113 \pm 0.004$ & $0.113 \pm 0.011$ & $0.109 \pm 0.002$ & $0.111 \pm 0.005$ & $0.151 \pm 0.004$ & $0.167 \pm 0.007$ & $0.193 \pm 0.011$ \\
\hline $\begin{array}{l}\mathrm{ZP} \\
(\mathrm{mV})\end{array}$ & $-24.34 \pm 2.05$ & $-24.38 \pm 1.92$ & $-24.25 \pm 2.54$ & $-24.25 \pm 0.93$ & $-24.22 \pm 1.63$ & $-24.22 \pm 0.48$ & $-19.77 \pm 0.80$ & $-17.43 \pm 0.50$ & $-15.07 \pm 0.20$ \\
\hline $\mathrm{pH}$ & $6.8 \pm 0.2$ & $6.8 \pm 0.2$ & $4.5 \pm 0.1$ & $6.8 \pm 0.2$ & $6.7 \pm 0.4$ & $6.7 \pm 0.3$ & $7.3 \pm 0.3$ & $7.5 \pm 0.2$ & $7.8 \pm 0.2$ \\
\hline $\begin{array}{l}\text { Assay } \\
(\%)\end{array}$ & $99.8 \pm 1.0$ & $99.4 \pm 1.0$ & $99.3 \pm 1.4$ & $98.1 \pm 0.7$ & $99.6 \pm 0.6$ & $99.4 \pm 1.4$ & $98.9 \pm 0.9$ & $98.1 \pm 0.5$ & $97.4 \pm 0.1$ \\
\hline \multicolumn{10}{|c|}{$4^{\circ} \mathrm{C} / \mathrm{Ambient}$ humidity } \\
\hline $\begin{array}{l}\text { PS } \\
(n m)\end{array}$ & $75.6 \pm 0.5$ & $75.3 \pm 0.4$ & $75.8 \pm 0.3$ & $75.7 \pm 0.5$ & $75.5 \pm 0.9$ & $75.7 \pm 0.6$ & $75.6 \pm 0.8$ & $76.0 \pm 0.2$ & $76.2 \pm 1.0$ \\
\hline PDI & $0.109 \pm 0.002$ & $0.110 \pm 0.003$ & $0.112 \pm 0.005$ & $0.113 \pm 0.010$ & $0.111 \pm 0.008$ & $0.111 \pm 0.006$ & $0.115 \pm 0.006$ & $0.112 \pm 0.010$ & $0.114 \pm 0.004$ \\
\hline $\begin{array}{l}\mathrm{ZP} \\
(\mathrm{mV})\end{array}$ & $-24.24 \pm 0.17$ & $-23.90 \pm 1.55$ & $-24.10 \pm 0.64$ & $-24.30 \pm 1.67$ & $-24.34 \pm 0.55$ & $-24.29 \pm 2.04$ & $-24.30 \pm 1.54$ & $-24.27 \pm 2.01$ & $-24.28 \pm 2.04$ \\
\hline $\mathrm{pH}$ & $6.8 \pm 0.1$ & $6.8 \pm 0.2$ & $6.9 \pm 0.1$ & $6.9 \pm 0.2$ & $6.8 \pm 0.2$ & $6.8 \pm 0.2$ & $6.8 \pm 0.1$ & $6.8 \pm 0.3$ & $6.7 \pm 0.3$ \\
\hline $\begin{array}{l}\text { Assay } \\
(\%)\end{array}$ & $100.1 \pm 0.6$ & $99.8 \pm 0.1$ & $99.6 \pm 1.2$ & $99.3 \pm 1.2$ & $99.8 \pm 0.5$ & $98.8 \pm 1.1$ & $99.5 \pm 1.5$ & $99.3 \pm 1.7$ & $100.0 \pm 0.8$ \\
\hline
\end{tabular}

Table 8. Oxidative stress parameters and cytokine levels on control and TNBS-induced rats $(n=8)$. 


\begin{tabular}{|c|c|c|c|c|c|c|}
\hline & Group A & Group B & Group C & Group D & Group E & Group F \\
\hline $\begin{array}{l}\text { NOx } \\
\mu \mathrm{mol} / \mathrm{g} \text { tissue }\end{array}$ & $2.92 \pm 0.23$ & $13.5 \pm 0.3$ & $3.29 \pm 0.19$ & $3.50 \pm 0.12$ & $14.0 \pm 0.4$ & $14.0 \pm 0.2$ \\
\hline $\begin{array}{l}\text { MDA } \\
\text { nmol/g } \\
\text { tissue }\end{array}$ & $3.23 \pm 0.40$ & $13.6 \pm 0.6$ & $5.26 \pm 0.59$ & $5.81 \pm 0.34$ & $13.22 \pm 0.40$ & $13.1 \pm 0.3$ \\
\hline $\begin{array}{l}\text { GSH } \\
\mu \mathrm{mol} / \mathrm{g} \\
\text { tissue }\end{array}$ & $\begin{array}{l}0.747 \pm \\
0.019\end{array}$ & $\begin{array}{l}0.186 \pm \\
0.014\end{array}$ & $\begin{array}{l}0.654 \pm \\
0.011\end{array}$ & $\begin{array}{l}0.637 \pm \\
0.005\end{array}$ & $\begin{array}{l}0.216 \pm \\
0.006\end{array}$ & $\begin{array}{l}0.206 \pm \\
0.007\end{array}$ \\
\hline TNF- $\mathbf{a}$ & $199.6 \pm$ & $1725.3 \pm$ & $203.7 \pm$ & $202.6 \pm$ & $1560.2 \pm$ & $1934.4 \pm$ \\
\hline & 26.0 & 127.2 & 32.3 & 32.3 & 38.6 & 117.3 \\
\hline IL-10 & & $116.3 \pm$ & & & $135.5 \pm$ & $192.9 \pm$ \\
\hline - & * & 5.2 & * & * & 9.9 & 11.4 \\
\hline IL-17 & & $52.3 \pm 2.0$ & & & $43.7 \pm 2.5$ & $46.1 \pm 1.1$ \\
\hline - & * & & * & * & & \\
\hline
\end{tabular}

* Lower than the detection limit of the ELISA kit $(34.6 \mathrm{pg} / \mathrm{ml}$ and $1.77 \mathrm{pg} / \mathrm{ml}$ for IL-10 and IL-17 respectively)

\section{Figures}

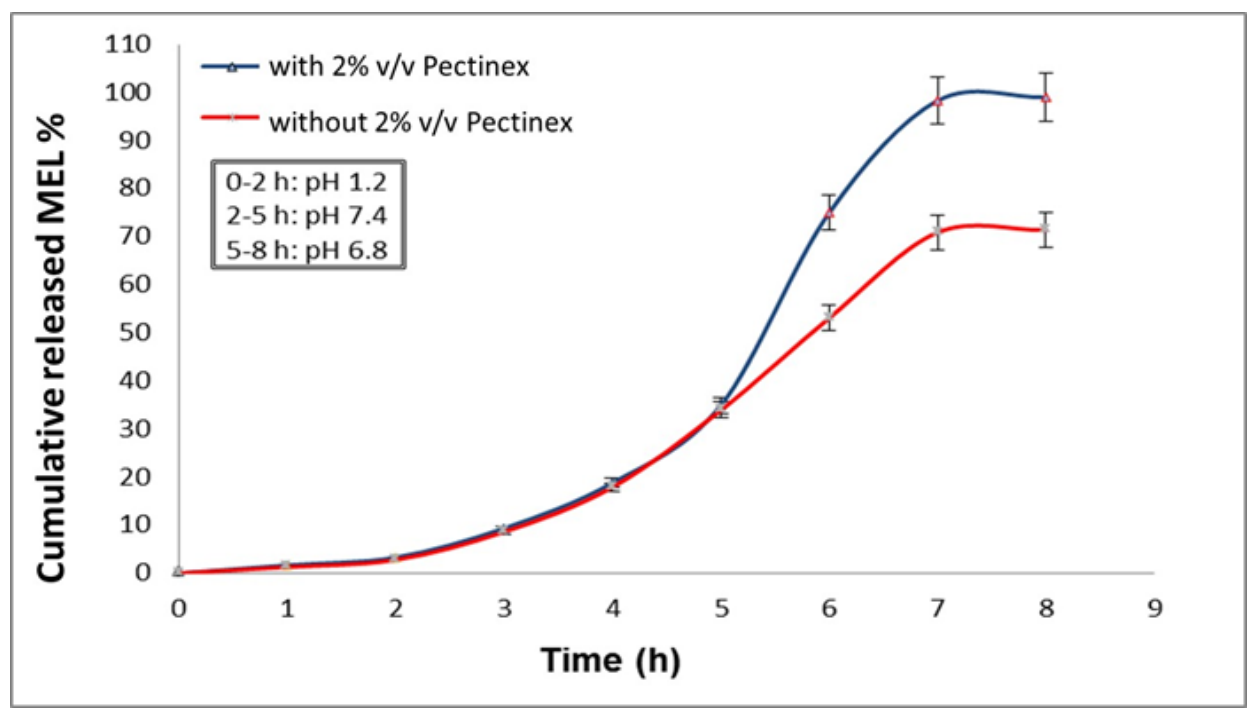

Figure 1

See the Supplemental Files section for the complete figure caption. 

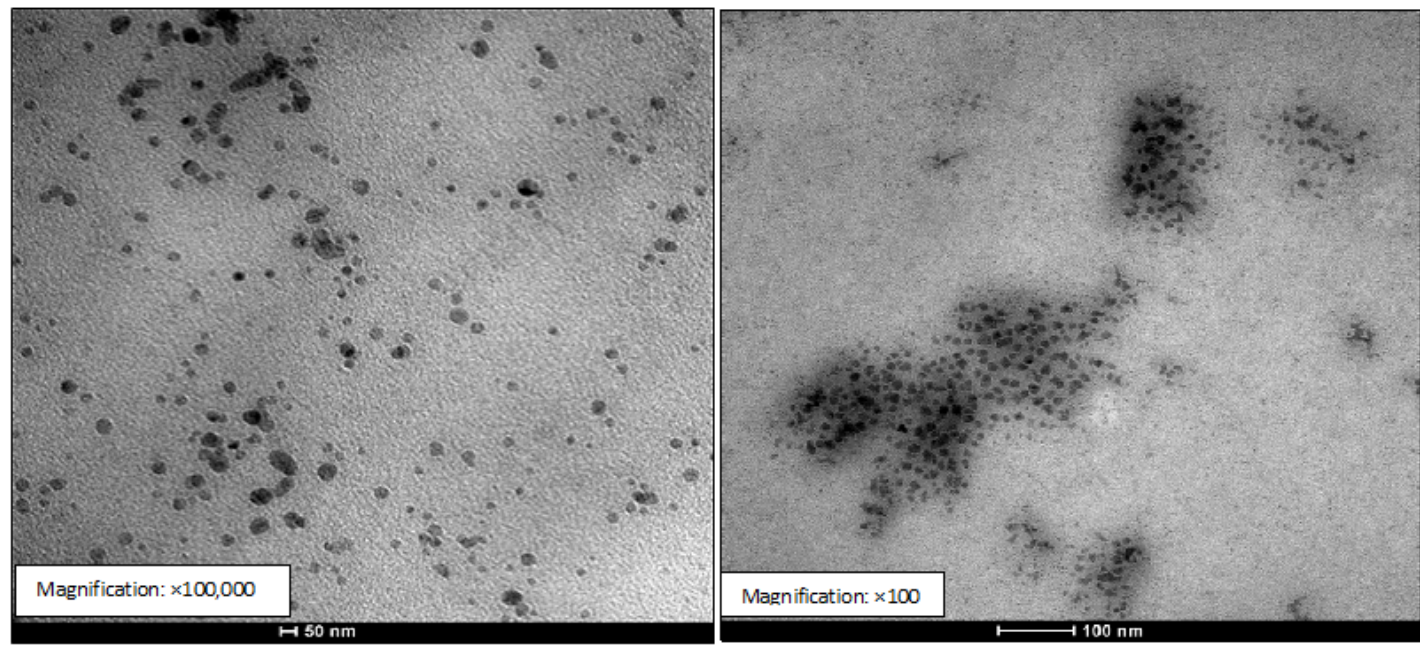

Figure 2

See the Supplemental Files section for the complete figure caption.
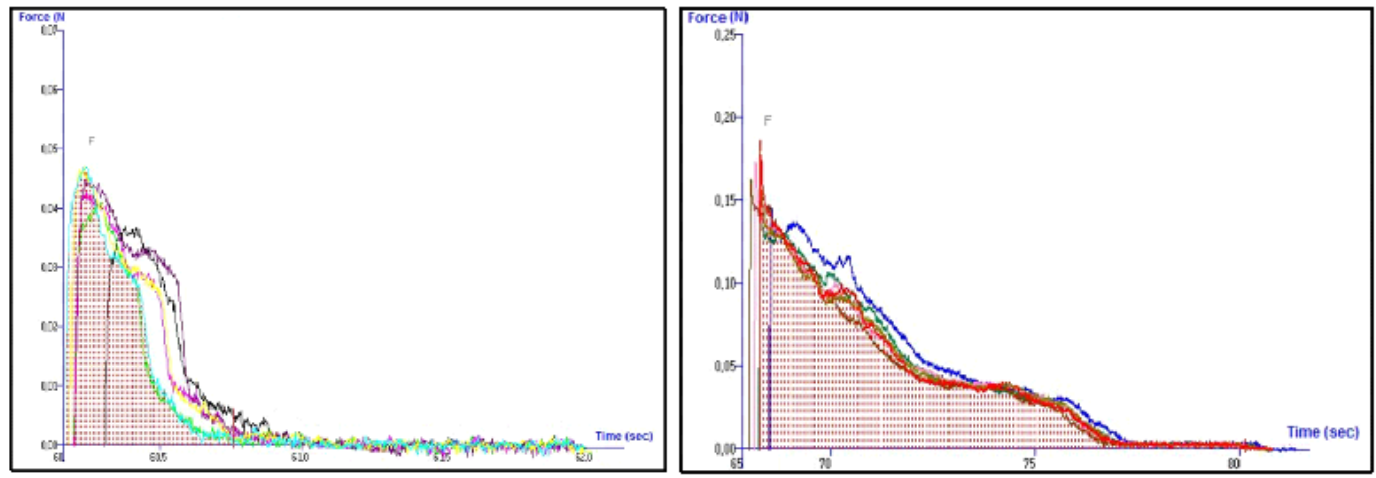

Figure 3

See the Supplemental Files section for the complete figure caption.
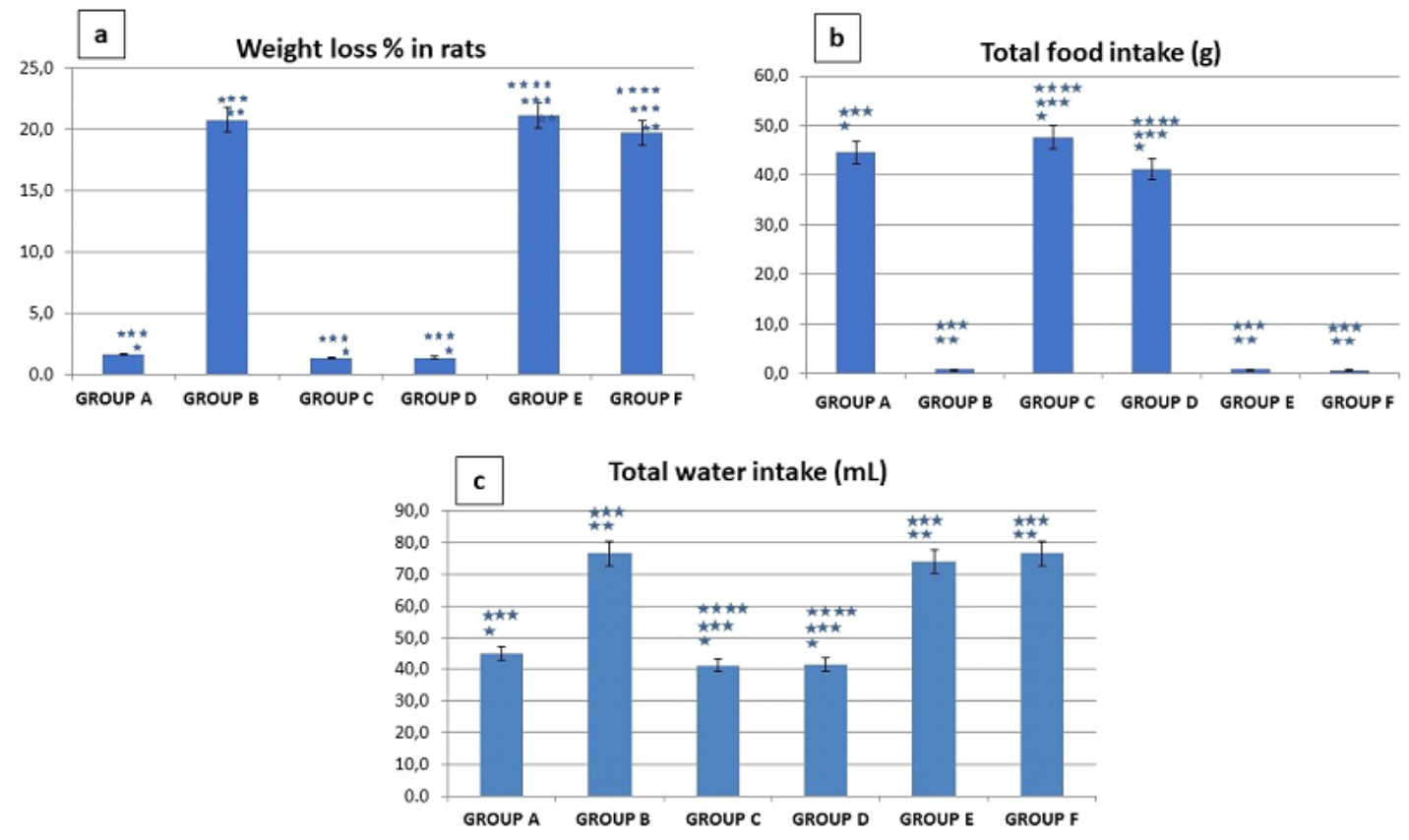

Figure 4

See the Supplemental Files section for the complete figure caption. 


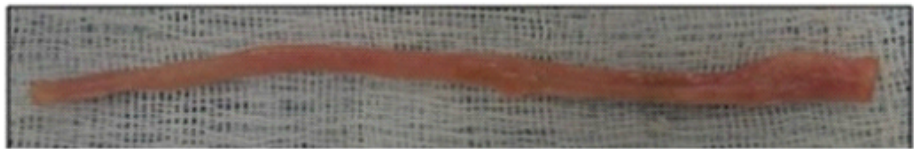

Group A: Control

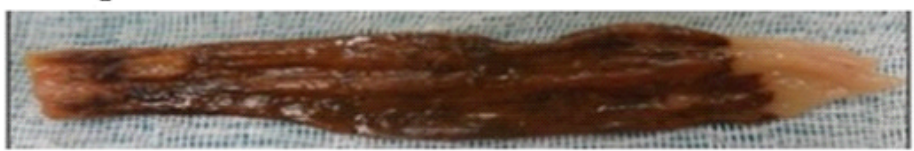

Group B: TNBS induced control

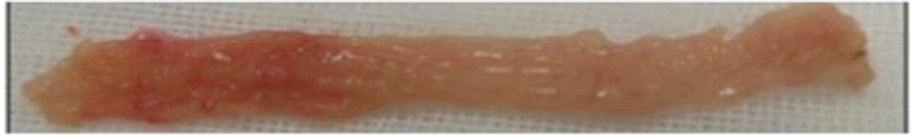

Group C: MEL loaded NP treatment via oral route

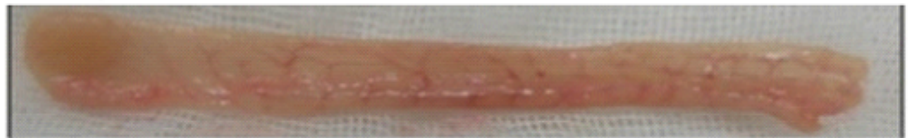

Group D: MEL loaded NP treatment via IC route

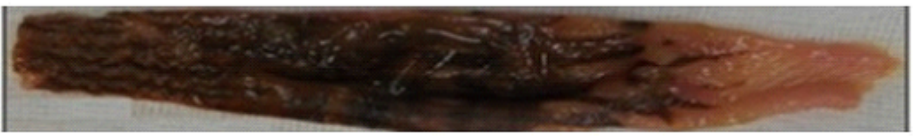

Group E: Blank NP treatment via oral route

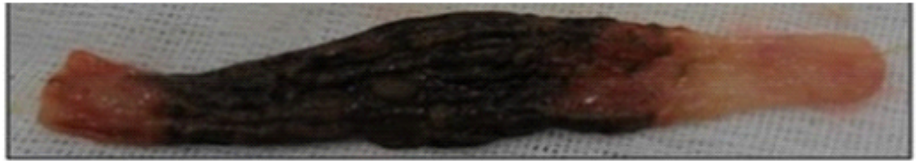

Group F: Blank NP treatment via IC route

Figure 5

See the Supplemental Files section for the complete figure caption.
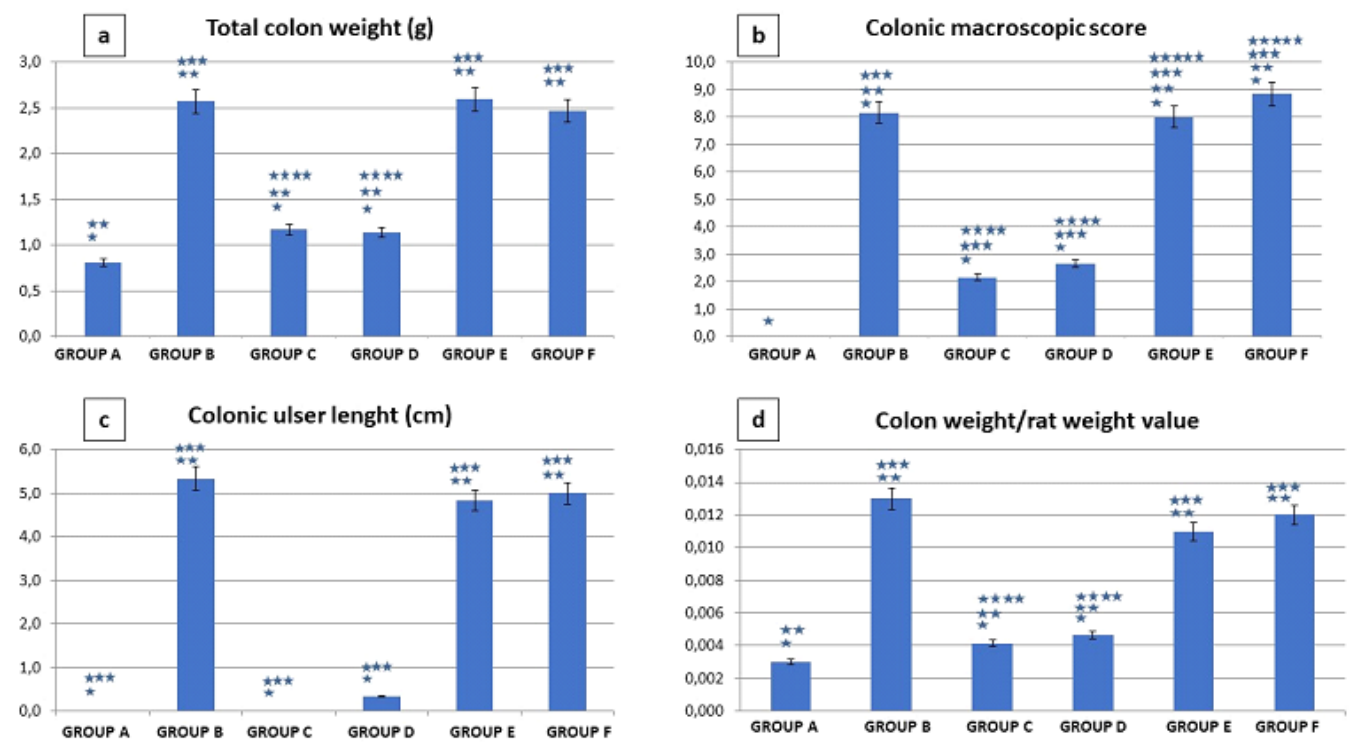

Figure 6

See the Supplemental Files section for the complete figure caption. 

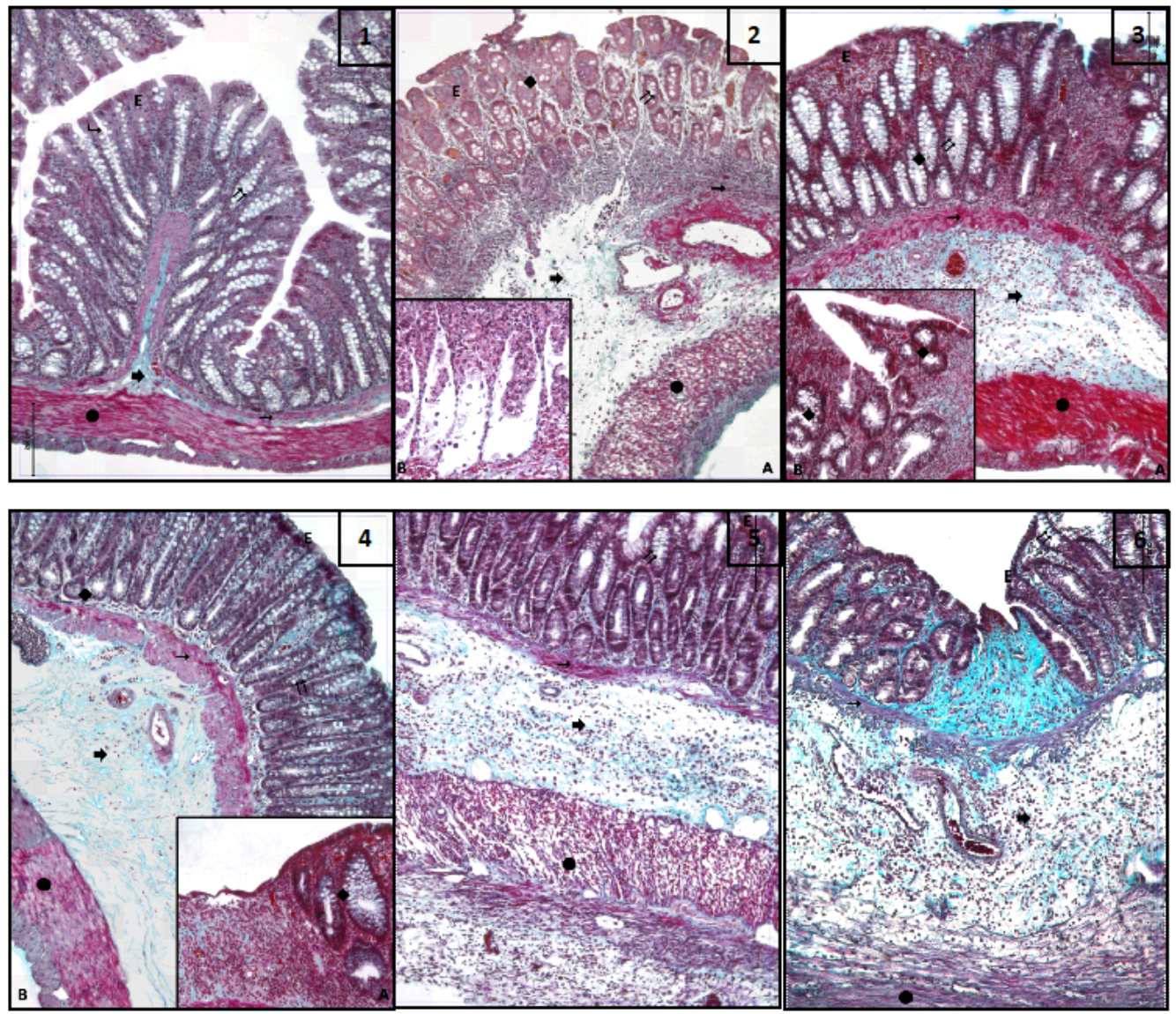

Figure 7

See the Supplemental Files section for the complete figure caption.

\section{Supplementary Files}

This is a list of supplementary files associated with this preprint. Click to download.

- GA.png

- Figurecaptions.docx 